\title{
DISCURSO DE GABRIELA MISTRAL AL RECIBIR EL GRADO DOCTOR HONORIS CAUSA EN LA UNIVERSIDAD DE CHILE*
}

* [Discurso] señor rector de la Universidad de Chile. Gabriela Mistral, 1954. Mecanuscrito con correcciones hológrafas en lápiz carbón. Colección Archivo del Escritor. Legado Gabriela Mistral, Biblioteca Nacional de Chile. 
SET̈EK RISCTOR DE LA UNIVERSIDAD DE OHILE

SENORAS Y SETORES:

Me aiento profundamente commovida y honrada por el alto hono: que esta Ilustro Universidad me ha concedido,grado demasiado importante para une simple y antigua maestra rural.

Siempre he tenido en alta consideración a esta Universidid Mater que me hospeda on este dfa, y hago votos para que su futuro sea aiempre tan claro $\mathrm{y}$ brillanto como ha sido su pasado.

Nosotros, profesionales, vivimos hasta on los peores casos, algunas ventajas aupadas a privilegios. Ellas no corresponden siempre a ealerios mayores sino a un mejor ambiente. Nuestros menesteres se desarrollan siempre dentro de ámbitos $\mathrm{SA}$ Áplos y a veces alegres.BI trabajo intelectual, si so pone en 61 un poco de organización- mejor dicho de arte -contiene grandes dulzuras ,y la mayor de ellas es la posibilidad de creación. Aunque la rutina suela llevarse 10 más del tiempo, aqui como en la especierfa, unos granos bastan para embalsamar ol dla vivido y la gota de la qreación que refrigera la vida toda.Pero ni la máquina ni la gleba regalan la libertad ni dejan márgen de tiempo o fuerza para ta/imaginación retoce como la nube suelta que hace $y$ deshace a gana.

Privilagiados son Uds y les corresponde pagar un diezmo que viene de lejos, que antes era leve y hoy pesa más . Expreso o tácito ets este devengar debe ser bien cumplido y aunque 61 no sea cobrado explicitamente, ol caso esefle pagar sin llamado ni presión alguna.

E1 profesional tanto como el artista, debe dar no s6lo su ciencia sino su amistad cotidiana, al hombre y a la mujer cuyas vidas son unos largos y anchos purgatorios. Porque la pobreza que se desliza a miseria en ciertas labores $y$ on climas fuertes de frio o de calor, mucho tieneh de purgas: que no purifican el cuerpo ni ayudan ol alma, que o exasperan 0 embrutecen por el tedio puro.Dije "amistad"pudiendo decir "ayuda" a secas, 
porque te trata de regalar alguna asistencia y companfa consoladora.Casi siempre el hombre culto resulta criatura fuerte y por lo tanto, capaz de confortar. Los recursos materiales son limitados, los del espiritu son mucho mayores de lo que creomos.si la jerarqufa social aignifica como dicen, una escala de valores, quínes manden en cualquior orden serán los más fuertes.

Nosotros, los 1 lamados intelectuales, debemos acercarnos al pueblo raso y gastar con El las horas que despilfarramos a vecestemitum tipo

delvida mund"; podemos, si, convivir con 61 frecuentemente, haciendo proseneia

on sus fiestas familiares, estando on sus nacimientos, sus Navidades y sus duelos. Tal cosa no soría hazaña sino rasa cristianidad y âtadura de las clases sueltas como los dados y alyjadasa unos de las otras. Aquello de las Patrias on cuanto a"familias nacionales ", no es metáora superlativa; cual más, cual menos, todos vivimos del pueblo, en formas diversas; 61 viene a ser algo asi como el segundo suelo que nos afirma y la segunda atmósfera on la cual respiramos medrando, por arradidura.

Ahora que ol odto corre ol munde vuelto ideologia,llevando encime hermosos nombres propios $y$ blandiendo $u$ ocultando ol garrote y el lazo,y euando la sordera de clase a clase ha parado on hábito empedernido, es preciso que aquellos cuyo oficio es el de pensar por encima del "compromiso"y la casta, se pongan a enmendar y a rectificar a toda prisa. En lo dicho, no me refiero ni de lejos a sembrar un almécigo ta mas de"lideriamo ". Esta búsqueda de 1as poblaciones huerfanas, este volver los ojos al campesinado debe ostar absolutamente limpio de correteos electorales y malicia de picaresca. Bn cuantos paises he andado, vi siempre que of juego entre ciudad y campo ,el confluir de lo urbano con lo rural, la fertilización de to uno por 10 otro, ha hecho las naciones mas sanas, mas compactas y estables. Y vi tambión lo contrarios las falsas"unidades"en las cuales ol campo se parece al jorobado o ol manco que vive amargado alimantando a sus parientes válidos , o sea 


\section{$-3-$}

a las ciudades-patronas, engrasadas de ocio,o en su ajetreo inútil parecen ardillas loces, cojidas de fuego.

Ha habido en nosotros un instinto que nos ha hecho no llegar on nuestras diferencias de partido a la brega sangrienta. Esa cordura permite que sobrevivan las patrias pequeగiss; cada ciudadano de ellas obra con la vigilancia y les tactol dol que maneja una vajilla de porcelana china. Cada piececilta es tan frágil como preciosa ,y no tiene repuesto:Son los pueblos que no deben perder nada, porque el destino les di6 poco.Y no han de travesear como otrís con la fantasia porque tienen lo justo o lo insuficiente.Como la granjora de ganancias sobra decir parvas,estas patrias no pueden despilfarraz el trabajo y no-o diga la sangre de sus hijos $y$ estas talvez sean las colectividades afligidas, las que yo quiero más, se llamen CHILE... Italia o BElgica o Dinamarca.

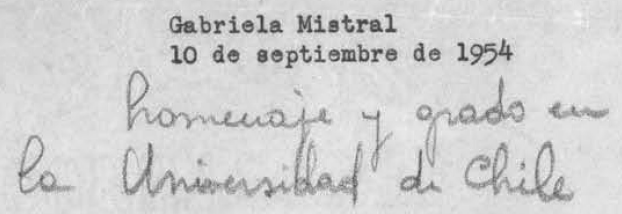

